\title{
Advantages of Thermococcus kodakaraenis (KOD) DNA Polymerase for PCR-Mass Spectrometry Based Analyses
}

\author{
Linda M. Benson, Allison P. Null, and David C. Muddiman \\ Department of Biochemistry and Molecular Biology and the W. M. Keck FT-ICR Mass Spectrometry Laboratory, \\ Mayo Proteomics Research Center, Mayo Clinic and Foundation, Rochester, Minnesota, USA
}

\begin{abstract}
The advantages of the thermostable DNA polymerase from Thermococcus kodakaraensis (KOD) are demonstrated for PCR amplification with subsequent detection by mass spectrometry. Commonly used DNA polymerases for PCR amplification include those from Thermus aquaticus (Taq) and Pyrococcus furiosus (Pfu). A 116 base-pair PCR product derived from a vWA locus was amplified by Taq, Pfu, or KOD DNA polymerase and compared by agarose gel electrophoresis and electrospray ionization Fourier transform ion cyclotron resonance mass spectrometry (ESI-FTICR-MS). KOD DNA polymerase demonstrated a 2- to 3-fold increase in PCR product formation compared to Pfu or Taq, respectively, and generated blunt-ended PCR product which allows facile interpretation of the mass spectrum. Additionally, we demonstrate the advantage of using high magnetic fields to obtain unit resolution of the same 116 base pair ( $\sim 72 \mathrm{kDa}$ ) PCR product at high $\mathrm{m} / \mathrm{z}$. (J Am Soc Mass Spectrom 2003, 14, 601-604) (C) 2003 American Society for Mass Spectrometry
\end{abstract}

$\mathrm{T}$ The use of electrospray ionization mass spectrometry (ESI-MS) for the detection and characterization of PCR products [1] (and references therein) has been shown to be important in the study of short tandem repeat (STR) and single nucleotide (SNP) polymorphisms. Whereas conventional electrophoresis indicates the approximate size of the PCR product based on its electrophoretic mobility in reference to a standard, mass spectrometry measures an intrinsic property of the PCR product (i.e., its mass) allowing for subsequent determination of base composition [2]. The amount of PCR product generated and the complexity of the resulting mass spectrum depend on the DNA polymerase utilized. Two of the most common polymerases used in PCR amplification are those derived from Thermus aquaticus (Taq) and Pyrococcus furiosus (Pfu). Table 1 shows the properties of these polymerases. Although both have been used successfully ([1] and references therein), there are some limitations for mass spectrometry based analysis. Thermococcus kodakaraensis (KOD) DNA polymerase (Table 1) combines high processivity, fidelity, and extension rate without the complexity introduced by terminal trans-

Published online April 17, 2003

Address reprint requests to Dr. D. C. Muddiman, Department of Biochemistry and Molecular Biology, Medical Sciences Building 3-115, Mayo Clinic and Foundation, 200 First Street, SW, Rochester, MN 55905, USA. E-mail: muddiman.david@mayo.edu

*Also at the Department of Chemistry, Virginia Commonwealth University, Richmond, Virginia 23284. ferase activity (TTA). The characterization of KOD DNA polymerase and its application to PCR has been demonstrated [3, 4]. Our goal was to capitalize on the established properties of KOD polymerase to generate PCR products for mass spectrometry based analyses. In this study, we performed the PCR amplification of the STR locus, vWA (116 bp) using Taq, Pfu, or KOD DNA polymerase. The resulting products were quantified by agarose gel electrophoresis and further characterized by ESI-Fourier transform ion cyclotron resonance-MS (ESIFTICR-MS). We have previously demonstrated chargestate resolution of a $309 \mathrm{kDa}$ PCR product at $4.7 \mathrm{~T}$ [5]. Herein, we demonstrate the ability to achieve broadband isotopic resolution of a $\sim 72 \mathrm{kDa}$ PCR product.

\section{Experimental}

The repeat region located within intron 40 of the von Willebrand factor (vWA) gene from an individual homozygous for Allele 18 was amplified from human genomic K562 DNA (Promega, Madison, WI). Each 50 $\mu$ PCR reaction contained $0.2 \mathrm{mM}$ each deoxynucleoside triphosphate (dNTP), 12.5 pmol each primer (forward sequence, 5'-TCA GTA TGT GAC TTG GAT TG-3'; reverse sequence, 5'-GAT AAA TAC ATA GGA TGG ATG G-3') (Midland Certified Reagent Co., Midland, TX) and $50 \mathrm{ng}$ of K562 DNA template unless otherwise stated. Each Taq reaction contained $10 \mathrm{mM}$ Tris- $\mathrm{HCl}, \mathrm{pH} 8.3,50 \mathrm{mM} \mathrm{KCl}, 1.5 \mathrm{mM} \mathrm{MgCl}_{2}$, and 1.25 
Table 1. Properties of experimental DNA polymerases

\begin{tabular}{|c|c|c|c|}
\hline & AmpliTaq & Pfu & KOD \\
\hline Extension rate & $2-4 \mathrm{~kb} / \mathrm{min}$ & $2-4 \mathrm{~kb} / \mathrm{min}$ & $6-8 \mathrm{~kb} / \mathrm{min}$ \\
\hline Processivity ${ }^{a}$ & $50-60$ bases & $15-20$ bases & $>300$ bases \\
\hline $\begin{array}{l}\text { 3'-5' Exonuclease } \\
\text { activity }^{\mathrm{b}}\end{array}$ & No & Yes & Yes \\
\hline $\begin{array}{l}\text { Terminal transferase } \\
\text { activity }^{c}\end{array}$ & Yes & No & No \\
\hline Fidelity ${ }^{d}$ & $1.3 \%$ & $0.39 \%$ & $0.38 \%$ \\
\hline
\end{tabular}

aProcessivity is the number of bases extended before the polymerase falls off the template.

bProofreading ability of the enzyme decreases the incorporation efficiency of modified dNTPs.

'TTA results in the non-template directed adenylation of the 3 ' termini. ${ }^{\mathrm{d}}$ Mis-incorporation rate of enzyme. An enzyme with $1.3 \%$ fidelity will result in 1.3 bases in 100 being incorrect.

units of AmpliTaq (Applied Biosystems, Foster City, CA). Each Pfu reaction contained $20 \mathrm{mM}$ Tris- $\mathrm{HCl}, \mathrm{pH}$ 8.8, $10 \mathrm{mM} \mathrm{KCl}, 10 \mathrm{mM}\left(\mathrm{NH}_{4}\right)_{2} \mathrm{SO}_{4}, 2 \mathrm{mM} \mathrm{MgSO}_{4}, 0.1 \%$ Triton, $0.1 \mathrm{mg} / \mathrm{ml}$ nuclease-free bovine serum albumin, and 1.25 units PfuTurbo polymerase (Stratagene, LaJolla, CA). Amplification of all PCR reactions utilized a MJ Research PTC-200 Thermal Cycler (Waltham, MA). Taq and Pfu reactions were incubated at an initial hold temperature of $95^{\circ} \mathrm{C}$ for 2 min followed by 30 cycles of $95^{\circ} \mathrm{C}$ for $15 \mathrm{~s}, 55^{\circ} \mathrm{C}$ for $30 \mathrm{~s}, 72{ }^{\circ} \mathrm{C}$ for $30 \mathrm{~s}$, and a final hold at $72{ }^{\circ} \mathrm{C}$ for $10 \mathrm{~min}$.

KOD reactions contained 0.25 units KOD Hot Start DNA polymerase (Novagen Inc, Madison, WI); KOD buffer (proprietary), $1 \mathrm{mM} \mathrm{MgSO}$, and 100, 50, 25, 10, or 5 ng K562 DNA. KOD reactions were incubated at an initial hold temperature of $95^{\circ} \mathrm{C}$ for 2 min followed by 30 cycles of $95^{\circ} \mathrm{C}$ for $15 \mathrm{~s}, 55^{\circ} \mathrm{C}$ for $30 \mathrm{~s}, 68^{\circ} \mathrm{C}$ for $10 \mathrm{~s}$, and a final hold of $68^{\circ} \mathrm{C}$ for $10 \mathrm{~min}$. PCR products were run on a $2 \%$ agarose gel stained with ethidium bromide $(0.5 \mu \mathrm{g} / \mathrm{ml})$ to visualize generated product. Gels were scanned (FX Molecular Imager, Bio-Rad, Hercules, CA) and differences in density of bands analyzed by Quantity One 1-D Analysis Software (Bio-Rad).

PCR products were ethanol precipitated $[6,7]$ and microdialyzed [8] prior to ESI-FTICR-MS [9]. Mass spectra were acquired in the negative-ion mode using a modified ESI-FTICR mass spectrometer (IonSpec Inc., Irvine, CA) with a 9.4 tesla superconducting magnet (Cryomagnetics, Oak Ridge, TN). The ESI emitter was a $50 \mu \mathrm{m}$ fused silica capillary pulled to a fine tip remotely coupled to a potential of $\sim 2200 \mathrm{~V}$ [10]. The PCR products were electrosprayed from a solution of 20: 20:60 isopropanol/10 $\mathrm{mM} \mathrm{NH}_{4} \mathrm{OAc}$ /acetonitrile with a final concentration of $20 \mathrm{mM}$ piperidine and imidazole $[11,12]$. The Taq, Pfu, and KOD products $(1 \mu \mathrm{M})$ were electrosprayed at a flow rate of $200 \mathrm{~nL} / \mathrm{min}$. Ions were accumulated externally in a rf-only hexapole for $2 \mathrm{~s}$ prior to injection and gated trapping in the cylindrical ICR cell [13]. Specific FT-ICR parameters are noted in the figure legends.

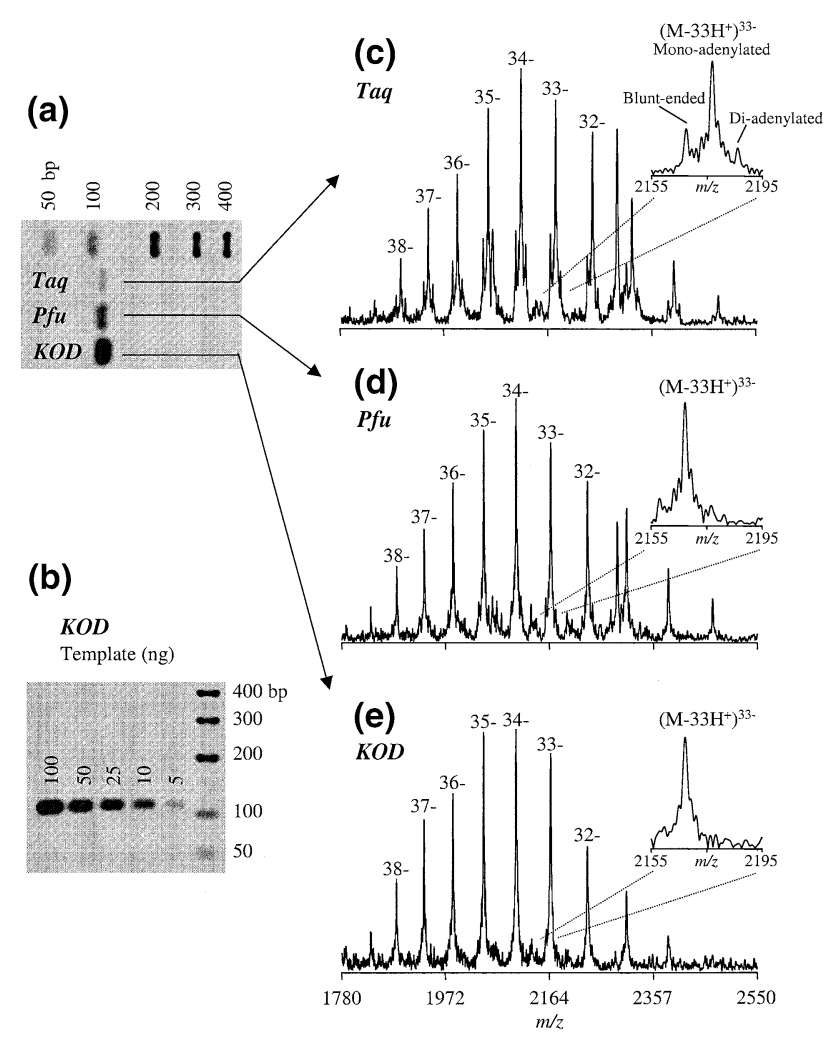

Figure 1. Comparison of vWA PCR products amplified by Taq, Pfu, and KOD DNA polymerases. (a) $2 \%$ agarose gel of the $116 \mathrm{bp}$ vWA product amplified from $50 \mathrm{ng}$ human genomic template. (b) $2 \%$ agarose gel comparing the amount of PCR product amplified from 100 to $5 \mathrm{ng}$ of genomic template. (c-e) ESI-FTICR mass spectra of the vWA PCR product $\left(\mathrm{MW}_{\text {average }}=71,533 \mathrm{Da}\right)$ amplified by Taq (c), Pfu (d), and KOD (e). Five $32 \mathrm{k}$ data point acquisitions, digitized at $500 \mathrm{kHz}$, were signal averaged and prior to fast-Fourier transform, the time domain was windowed using the Hanning function and zero filled twice.

\section{Results and Discussion}

Table 1 describes the properties of the DNA polymerases used in this study $[1,4]$. The higher extension rate (2- to 4-fold) of KOD compared to Taq or Pfu results in a shorter amplification time to generate an equivalent amount of amplicon. Processivity, the number of nucleotides extended before the polymerase detaches, is 5-20 times higher for KOD compared to Taq or Pfu. This property along with the exonuclease activity of KOD decreases the chance of mis-incorporation of nucleotides during the PCR amplification. TTA found in Taq polymerase results in the 3'-adenylation of the PCR products forming three different species: Bluntended, mono-adenylated, and di-adenylated. KOD polymerase lacks TTA and therefore generates only a blunt-ended PCR product. Collectively, these properties are important for forming a single and accurate copy of the original template.

Figure 1a shows a gel comparing PCR product from Taq, Pfu, and KOD using $50 \mathrm{ng}$ of genomic DNA template. Enzyme amounts for Taq, Pfu, and KOD were $1.25,1.25$, and 0.25 units/reaction, respectively. An 
increase in the amount of KOD enzyme did not produce more KOD generated amplicon (data not shown). The gel revealed a 2- to 3-fold increase of KOD generated amplicon compared to Taq or Pfu, respectively, as measured by densitometry. DNA concentration measured by UV absorbance of the ethanol precipitated/ microdialyzed amplicon also demonstrated a 2- to 3-fold increase in KOD product. Comparable results of increased KOD product versus Taq or Pfu amplified product have been noted for other loci in our laboratory. Specifically, KOD and Taq were used to generate a 500-base pair PCR product from $1 \mathrm{ng}$ of whole bacteriophage $\lambda$ DNA template. The KOD polymerase consistently produced a 2-4 increase of product over Taq as quantified by agarose gel analysis (data not shown). Amplification with KOD polymerase of exon 3 of the transthyretin receptor gene from $1 \mathrm{ng}$ of human genomic template (K562 DNA) has also proven successful and reproducible (data not shown).

Figure $1 \mathrm{~b}$ shows a gel of the amplicon generated from the vWA locus with KOD starting with different amounts of K562 DNA template. Product is observed on the gel at template levels as low as $5 \mathrm{ng}(\sim 1500$ copies genomic template). This result is significant for cases when the genomic template available for amplification is limited (e.g., laser microdissection, forensic evidence). We have previously demonstrated the detection of an 82 base-pair PCR product by ESI-FTICR-MS when electrosprayed from a $5 \mathrm{nM}$ solution [14]. However, numerous reports have pooled several PCR reactions in order to allow detection of the amplicon using mass spectrometry. KOD clearly generates more product from less template which eliminates the need for pooling multiple reactions.

Figure 1c, d, and e compare the ESI-FTICR-MS mass spectra of the Taq, Pfu, and KOD amplified vWA products from $50 \mathrm{ng}$ of genomic DNA. The expansion plot of the $\left(\mathrm{M}-33 \mathrm{H}^{+}\right)^{33-}$ charge state is shown for each spectrum. The spectrum in Figure 1c demonstrates the complexity of the data for the vWA amplicon when Taq DNA polymerase was used. The ion abundance is dispersed over three molecular species: Blunt-ended, mono-adenylated, and di-adenylated, resulting in a more complex, less abundant, mass spectrum. Although the processivity for Pfu DNA polymerase amplification is lower than Taq, the lack of TTA results in the formation of a blunt-ended amplicon (i.e., the signal is not dispersed over three molecular species). The mass spectrum of the vWA product generated with KOD DNA polymerase in Figure 1e also demonstrated one molecular ion species as predicted for an individual homozygous for allele 18 at the vWA locus.

KOD DNA polymerase has one distinct disadvantage; the incorporation of modified bases is not efficient due to the proofreading activity of the enzyme. Taq DNA polymerase or a modified Pfu polymerase lacking exonuclease activity (e.g., Pfu exo-) would be needed in such studies. For example, Taq polymerase allowed the incorporation of 7-deazaguanosine into an 82 base-pair

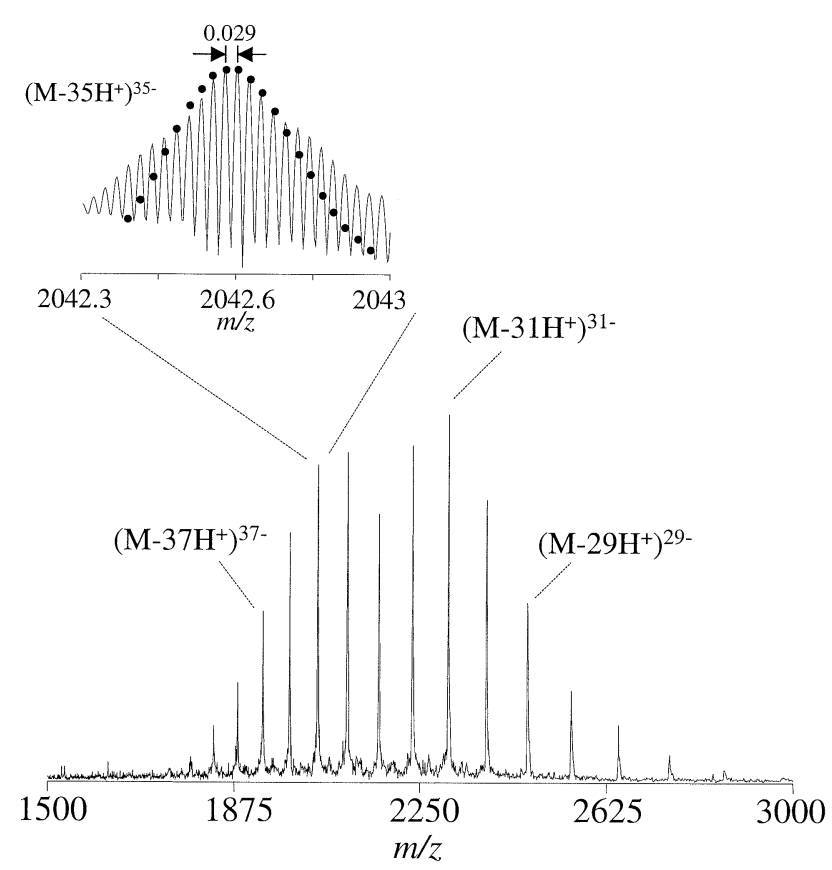

Figure 2. Broadband, single acquisition ESI-FTICR mass spectrum of the $116 \mathrm{bp}$ vWA PCR product demonstrating unit resolution of the $\left(\mathrm{M}-35 \mathrm{H}^{+}\right)^{35-}$ charge state ion $(\mathrm{m} / \mathrm{z}$ isotopic spacing $=$ 0.029) achieved using time-domain sampling [21]. The "dots" represent the theoretical isotopic distribution for this multiplecharged molecular ion. The 1 Mbyte dataset was digitized at 500 $\mathrm{kHz}$ which results in a theoretical, zero-pressure limit, resolving power of $120,000_{\text {FWHM }}$ [23] while the experimental resolving power of this spectrum was determined to be $\sim 108,000_{\mathrm{FWHM}}$.

PCR product [1] in an effort to reduce the number of fragmentation pathways; the latter was recently demonstrated using synthetic oligonucleotides [15].

The significant advantages of using KOD over Taq or Pfu for PCR mass spectrometry based analyses are the increased production of a single blunt-ended species over a shorter reaction time. This is especially important for the ESI-MS analysis of larger PCR products.

The benefit of generating one molecular species in PCR can be combined with the advantage of using high magnetic fields in FTICR-MS [16] and eventually, using isotope-depleted ddNTP's in the PCR phase (as has been shown for protein analysis [17]), to allow the isotopic resolution of PCR products and monoisotopic, accurate mass determination using a dual-ESI source $[18,19]$. Marshall and coworkers have previously demonstrated resolving power as high as 8,000,000 for a protein of $8.6 \mathrm{kDa}$ [20] while McLafferty and coworkers demonstrated unit mass resolution of a $112 \mathrm{kDa}$ protein [21]; the latter is somewhat more challenging due to the long isotopic beat period [22]. In these studies [21], the researchers resolved the isotopes of the 91+ chargestate $(m / z \sim 1237)$ of a $112 \mathrm{kDa}$ protein which has an isotopic beat period of $\sim 0.5 \mathrm{~s}$ ! A mass resolving power of $\sim 170,000$ was achieved by lowering the ion density prior to detection and summing 50 spectra [21].

Figure 2 shows the single acquisition mass spectrum obtained for a $\sim 72 \mathrm{kDa}$ PCR product (duplex form) 
obtained at 9.4 tesla. The inset clearly demonstrates that unit mass resolution was achieved. The isotopic beat period [22] for the $35-$ charge state is $\sim 1 \mathrm{~s}$ at 9.4 tesla (i.e., the different isotopic members are undergoing destructive interference for nearly a second, during which time no analytical signal is being generated). Therefore, the experimental broadband resolving power of $\sim 108,000_{\mathrm{FWHM}}$ at $\mathrm{m} / \mathrm{z}=2043$, for which the low charge-states observed are attributed to the chargestate reduction properties of piperidine [11, 12], is quite challenging as detection of ions at higher $\mathrm{m} / \mathrm{z}$ (lower charge-states) results in a linear increase in the isotopic beat period [22] and concomitant decrease in resolving power [23].

\section{Acknowledgments}

The authors thank M. Cristine Charlesworth for assistance with densitometry analysis of the gel bands. They gratefully acknowledge the financial support of the National Institutes of Health (R01HG02159), the W. M. Keck Foundation, the Mayo Clinic and Foundation, the Department of Chemistry (Mary E. Kapp Foundation), and Virginia Commonwealth University. APN thanks the American Chemical Society, Division of Analytical Chemistry, for the Graduate Student Summer Fellowship sponsored by the Society for Analytical Chemists of Pittsburgh.

\section{References}

1. Null, A. P.; Muddiman, D. C. Perspectives on the Use of Electrospray Ionization Fourier Transform Ion Cyclotron Resonance Mass Spectrometry for Short Tandem Repeat Genotyping in the Post-Genome Era. J. Mass Spectrom. 2001, 36, 589-606.

2. Muddiman, D. C.; Anderson, G. A.; Hofstadler, S. A.; Smith, R. D. Length and Base Composition of PCR-Amplified Nucleic Acids Using Mass Measurements from Electrospray Ionization Mass Spectrometry. Anal. Chem. 1997, 69, 1543-1549.

3. Mizuguchi, H.; Nakatsuji, M.; Fujiwara, S.; Takagi, M.; Imanaka, T. Characterization and Application to Hot Start PCR of Neutralizing Monoclonal Antibodies Against KOD DNA Polymerase. J. Biochem. 1999, 126, 762-768.

4. Takagi, M.; Nishioka, M.; Kakihara, H.; Kitabayashi, M.; Inoue, H.; Kawakami, B.; Oka, M.; Imanaka, T. Characterization of DNA Polymerase from Pyrocoous sp. Strain KOD1 and Its Application to PCR. Appl. Environ. Microbiol. 1997, 63, $4504-4510$.

5. Muddiman, D. C.; Null, A. P.; Hannis, J. C. Precise Mass Measurement of a Double-Stranded 500 Base-Pair (309 kDa) Polymerase Chain Reaction Product by Negative Ion Electrospray Ionization Fourier Transform Ion Cyclotron Resonance Mass Spectrometry. Rapid Commun. Mass Spectrom. 1999, 13, 1201-1204.

6. Stults, J. T.; Marsters, J. C. Improved Electrospray Ionization of Synthetic Oligodeoxynucleotides. Rapid Commun. Mass Spectrom. 1991, 5, 359-363.

7. Limbach, P. A.; Crain, P. F.; McCloskey, J. A. Molecular Mass Measurement of Intact Ribonucleic Acids via Electrospray Ionization Quadrupole Mass Spectrometry. J. Am. Soc. Mass Spectrom. 1995, 6, 27-39.

8. Liu, C.; Muddiman, D. C.; Tang, K.; Smith, R. D. Improving the Microdialysis Procedure for Electrospray Ionization-Mass
Spectrometry of Biological Samples. J. Mass Spectrom. 1997, 32, $425-431$.

9. Hannis, J. C.; Muddiman, D. C. Accurate Characterization of the Tyrosine Hydroxylase Forensic Allele 9.3 Through Development of Electrospray Ionization Fourier Transform Ion Cyclotron Resonance Mass Spectrometry. Rapid Commun. Mass Spectrom. 1999, 13, 954-962.

10. Hannis, J. C.; Muddiman, D. C. Nanoelectrospray Mass Spectrometry Using Non-Metalized Tapered $(50-10 \mu \mathrm{m})$ FusedSilica Capillaries. Rapid Commun. Mass Spectrom. 1998, 12, 443-448.

11. Greig, M.; Griffey, R. H. Utility of Organic Bases for Improved Electrospray Mass Spectrometry of Oligonucleotides. Rapid Commun. Mass Spectrom. 1995, 9, 97-102.

12. Muddiman, D. C.; Cheng, X. H.; Udseth, H. R.; Smith, R. D. Charge-State Reduction with Improved Signal Intensity of Oligonucleotides in Electrospray Ionization Mass Spectrometry. J. Am. Soc. Mass Spectrom. 1996, 7, 697-706.

13. Senko, M. W.; Hendrickson, C. L.; Emmett, M. R.; Shi, S. D.-H.; Marshall, A. G. External Accumulation of Ions for Enhanced Electrospray Ionization Fourier Transform Ion Cyclotron Resonance Mass Spectrometry. J. Am. Soc. Mass Spectrom. 1997, 8, 970-976.

14. Hannis, J. C.; Muddiman, D. C. Detection of Double-Stranded PCR Amplicons at the Attomole Level Electrosprayed from Low Nanomolar Solutions using FT-ICR Mass Spectrometry. Fresenius J. Anal. Chem. 2001, 369, 246-251.

15. Hannis, J. C.; Muddiman, D. C. Tailoring the Gas-Phase Dissociation and Determining the Relative Energy of Activation for Dissociation of 7-Deaza Modified Oligonucleotides Containing a Repeating Motif. Int. J. Mass Spectrom. Ion Processes 2002, 219, 139-150.

16. Marshall, A. G.; Guan, S. H. Advantages of High Magnetic Field for Fourier Transform Ion Cyclotron Resonance Mass Spectrometry. Rapid Commun. Mass Spectrom. 1996, 10, 1819 1823.

17. Marshall, A. G.; Senko, M. W.; Li, W. Q.; Li, M.; Dillon, S.; Guan, S. H.; Logan, T. M. Protein Molecular Mass to 1 Da by C-13, N-15 Double-Depletion and FT-ICR Mass Spectrometry. J. Am. Chem. Soc. 1997, 119, 433-434.

18. Hannis, J. C.; Muddiman, D. C. A Dual Electrospray Ionization Source Combined with Hexapole Accumulation to Achieve High Mass Accuracy of Biopolymers in Fourier Transform Ion Cyclotron Resonance Mass Spectrometry. J. Am. Soc. Mass Spectrom. 2000, 11, 876-883.

19. Flora, J. W.; Hannis, J. C.; Muddiman, D. C. High-Mass Accuracy of Product Ions Produced by SORI-CID Using a Dual Electrospray Ionization Source Coupled with FTICR Mass Spectrometry. Anal. Chem. 2001, 73, 1247-1251.

20. Shi, S. D.; Hendrickson, C. L.; Marshall, A. G. Counting Individual Sulfur Atoms in a Protein by Ultrahigh-Resolution Fourier Transform Ion Cyclotron Resonance Mass Spectrometry: Experimental Resolution of Isotopic Fine Structure in Proteins. Proc. Natl. Acad. Sci. U.S.A. 1998, 95, 11532-11537.

21. Kelleher, N. L.; Senko, M. W.; Siegel, M. M.; McLafferty, F. W. Unit Resolution Mass Spectra of 112 kDa Molecules with $3 \mathrm{Da}$ Accuracy. J. Am. Soc. Mass Spectrom. 1997, 8, 380-383.

22. Hofstadler, S. A.; Bruce, J. E.; Rockwood, A. L.; Anderson, G. A.; Winger, B. E.; Smith, R. D. Isotopic Beat Patterns in Fourier Transform Ion Cyclotron Resonance Mass Spectrometry-Implications for High Resolution Mass Measurements of Large Biopolymers. Int. J. Mass Spectrom. Ion Processes 1994, 132, 109-127.

23. Marshall, A. G.; Hendrickson, C. L.; Jackson, G. S. Fourier Transform Ion Cyclotron Resonance Mass Spectrometry: A Primer. Mass Spectrom. Rev. 1998, 17, 1-35. 